\title{
PREVALENCE OF CUMULATIVE HAND TRAUMA DISORDERS IN PIANISTS
}

Khushboo Tahilram ${ }^{1}$, Sanket Nagrate ${ }^{* 2}$, Ashok Shaym ${ }^{3}$, Parag Sancheti 4 .

${ }^{1}$ BPTh student, Sancheti Institute College of Physiotherapy, Pune, Maharashtra, India.

*2 PT, Sancheti Institute College of Physiotherapy, Pune, Maharashtra, India.

${ }^{3}$ MS ORTHO, Research officer, Sancheti Institute of Orthopedics And Rehabilitation, Pune, Maharashtra, India.

${ }^{4}$ MS ORTHO, Chairman, Sancheti Institute of Orthopedics And Rehabilitation, Pune, Maharashtra, India.

\section{ABSTRACT}

Background: The professional musician is required to practice daily for an average of about six to eight hours. Practice sessions would typically require the artist to use the same muscles repeatedly. Factors such as poor playing postures and inadequate rest periods predispose artists to repetitive stress injuries over a period of time.

Context and purpose of study: The profession of piano playing involves the meticulous use of the various intrinsic muscles of the hand. Repeated exposure to micro trauma over a period of time has a direct effect on performance as a level of speed and precision has to be maintained at all times. Therefore this study was aimed at finding out the effect of the prevalence of cumulative hand trauma disorders faced by pianists.

Results: The result of the study carried out showed that $68 \%$ of subjects experienced pain in the hand. A majority of $20 \%$ of the subjects experienced pain at the site of their wrist. Finkelsteins test was positive in $34 \%$ of subjects with pain. The average grip strength taken for males was $37.67 \mathrm{~kg}$ 's and $20.18 \mathrm{kgs}$ in females. Beighton's scale for hypermobility was taken and $76 \%$ of subjects tested positive.

Conclusion: In conclusion this study reveals that pianists are predisposed to cumulative hand trauma disorders. With the help of the outcome measure's discussed in the results we are able observe that grip strength is significantly reduced, DeQuervain's is positive and hypermobility does occur in a particularly large amount of the subject population. Using Hoppmann's (1998) pain outcome measure we can conclude that pain does affect the professional performance in a negative way.

KEY WORDS: Overuse Syndromes, Pianists, Hand Trauma.

Address for correspondence: Dr. Sanket Nagrate, Sancheti Institute of Orthopedics And Rehabilitation, Pune, Maharashtra, India. E-Mail: nagralesanket@gmail.com

Quick Response code

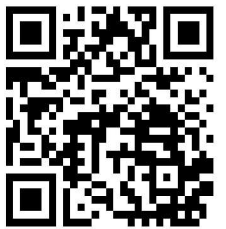

DOI: $10.16965 /$ ijpr.2018.138
Journal Information

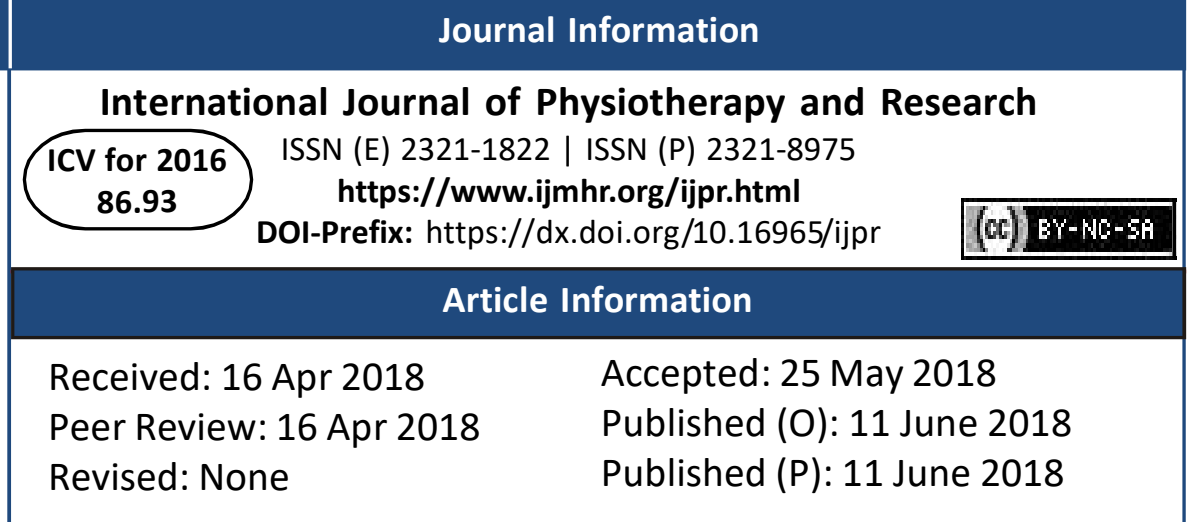

\section{INTRODUCTION}

The profession of piano playing, is one which involves the meticulous use of the various intrinsic muscles of the hand therefore, invariably exposing these professionals to cumulative hand trauma disorders. This repeated exposure to microtrauma over a period of time has a direct effect on the performance of these individuals as they are always required to maintain a level of speed and precision [1]. Many performers are unaware of the effect that overworking the muscles in their arms will have on their hands. 
They do not know that the muscles in the forearm are largely responsible for controlling movements in the hand. A contributing factor is that there is fierce competition for work, musicians may therefore be hesitant to complain about an injury or impairment [2].

One of the most common problems in musicians as quoted by Lederman RJ, in his paper on Neuromuscular problems in musicians, is overuse which is poorly defined but represents the culmination of playing past the point of muscle fatigue. Factors that may contribute to the incidence of playing related injuries appear to include biomechanical inefficiency of wrist, finger, elbow and shoulder postures and movements, extremely long hours of practice. There is insufficient regard for the characteristics of and structural differences between individual pianos [3].

Pianists' musculoskeletal complaints commonly include tendonitis, overuse syndrome, carpal tunnel syndrome at the wrist and radial nerve compression at the elbow (Harding, Brandt, \& Hillberry, 1989). Professional pianists are at risk of playing related musculoskeletal disorders, which include mainly soft tissue (muscle, ligament and tendon) conditions related to mechanical strain, but may also involve bone, cartilage and nerves, with such symptoms being experienced as pain and loss of function that relate specifically to piano playing [3].

Lifestyle choices further contribute to higher risk for RSI. Lengthy practice sessions are customary, with short interruptions for fast foods, caffeine or nicotine breaks caffeine. The musician may be unwilling to seek medical help early, because he or she is concerned that the physician will require the limitation of practice or performance times, or worse: Instruct the musician to stop playing altogether. In addition, there is a social/work ethic concern about the label of an injured musician [8].

Aims and objectives: The aim of this study was to determine the prevalence of hand trauma disorders in pianists and its' effect on their performance levels on a daily basis.

\section{MATERIALS AND METHODS}

Study population: A total of 50 professional piano players were taken for this study, this included 23 females and 27 males. The average age of all pianists being 33.87 years and the average number of years of all pianists playing the instrument being 11.75 years. In order to meet the selection criteria each individual had to be playing the piano for three years or more and had to never have experienced an upper limb injury i.e fractures and muscular diseases.

Data collection methodology: An adequate amount of research surrounding the topic was done. The study design together with consent forms informing participants about the need for the study and their right to retract from the study at any point together with a self designed questionnaire (Table 1 ) was reviewed and accepted by the institutional ethical reviewing committee. Each subject was then assessed.

\section{Table 1}

\section{Questions:}

1) Do you experience any kind of pain in your hands?

2) If yes, please mark the site on the following diagram ( anatomical diagram of the hand was provided)

3) Please rate your pain on the following scale (Hoppmann's 1998)

4) Special tests: Finkelstein's test for Dequervain's

5) Grip strength-Right and left using a (handheld dynamometer)

6) Beighton's scale for hypermobility

The first question asked if subjects experienced any kind of pain, if they answered yes they were then asked to mark their exact location of pain on a provided anatomical picture of the hand. Thereafter, subjects were asked to rate their pain using Hoppman's pain rating scale [4].

Finkestein's test for Dequervain's tendonitis was checked in the appropriate position in all subjects.

Grip strength using a hand held dynamometer was assessed in subjects in the standing position with a straight back, the shoulder adducted and in neutral rotation, the elbow flexed to $90^{\circ}$,the lower arm in neutral position and the wrist in neutral position [5]. The best out of three readings was considered. Thereafter Beighton's scale for hypermobility was checked in all subjects and scored out of 9 . 
All data was entered into Microsoft Office Excel 2007 and results were analysed using demographic data. In order to analyse and compare the grip strength readings the IBM SPSS version 17 software was used, the MannWhitney $U$ test was applied.

\section{RESULTS}

The response rate of this study was a total of 50 (27 males and 23 females). The number of years playing the piano of all subjects was 11.25 years. The result of the study carried out showed that $68 \%$ of subjects experienced pain in the hand. A majority of $20 \%$ of the subjects experienced pain at the site of their wrist. Finkelsteins test was positive in $34 \%$ of subjects with pain. The average grip strength taken for males was 37.67 kg's and $20.18 \mathrm{kgs}$ in females. Beighton's scale for hypermobility was taken and $76 \%$ of subjects tested positive.

This study showed a positive correlation between age and pain of .001. This was demonstrated by using a point biserial correlation. As the age of subjects increased the likelier they were to experience pain.

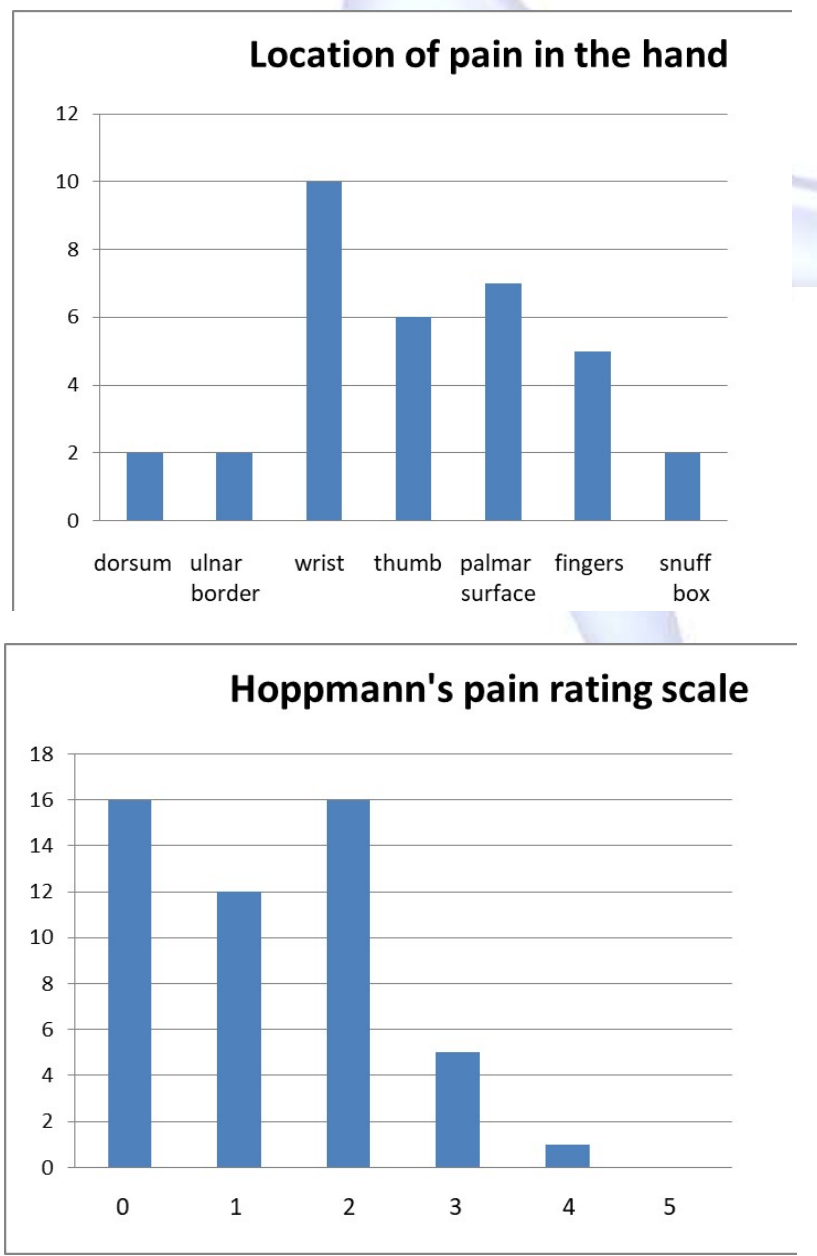

\section{Incidence of pain in the hand}
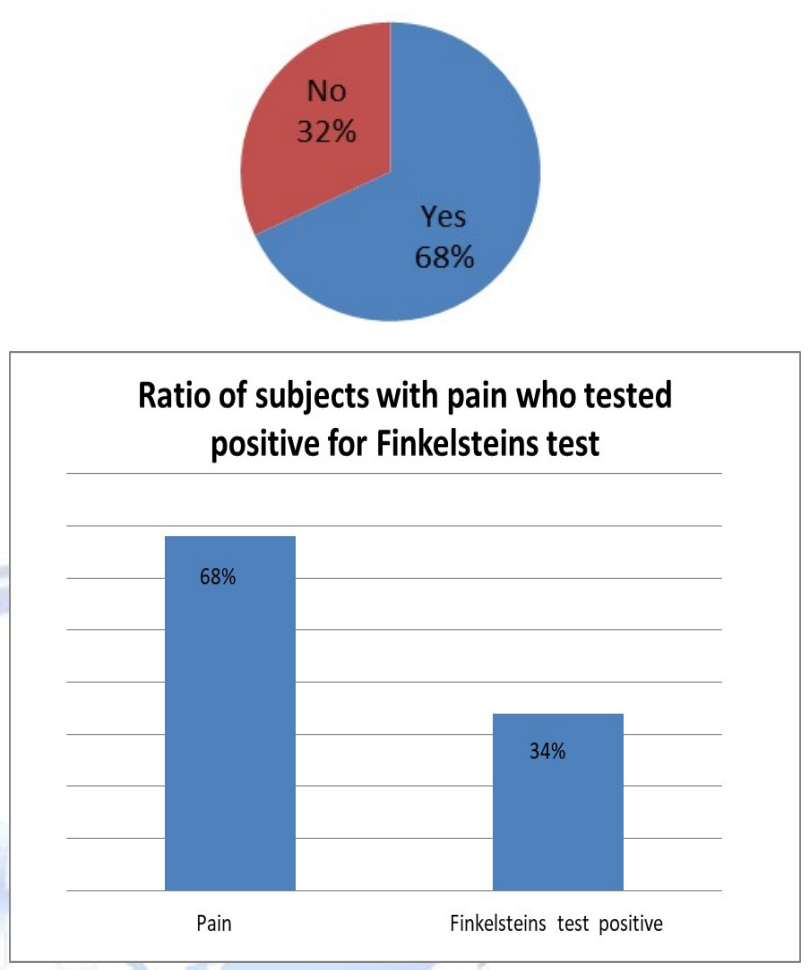

DISCUSSION

This study was conducted in order to observe whether pianists suffer from cumulative hand trauma disorders due to repetitive overuse of the same musculature. A total of 50 subjects were included in these study 27 males and 23 females. The discrepancy between the genders may be attributed to the smaller anatomy of and diminished muscle mass in women [6].

It was observed that $68 \%$ of all subjects included in this study experienced pain in the hand. Lippmann H.A demonstrated that approximately $25 \%$ of musicians often experience playing related injuries [7].

Hand and wrist injuries are particularly common in performers, especially pianists and string players [6]. Of the $68 \%$ of subjects who experienced pain $20 \%$ answered that they experience pain in the wrist region. A grading scale used to assess the severity of injury specific to pianists (Hoppmann's 1998) revealed that Grade 2 was experienced by $32 \%$ of the subjects, this parameter states that the subject experiences pain for a prolonged period after playing the piano. Pianists' musculoskeletal complaints commonly 
include tendonitis, overuse syndrome, carpal tunnel syndrome at the wrist and radial nerve compression at the elbow (Harding, Brandt, \&Hillberry, 1989). Both professional pianists and non professional piano players are at risk of playing related musculoskeletal disorders (PRMDs), which include mainly soft tissue (muscle, ligament and tendon) conditions related to mechanical strain, but may also involve bone, cartilage and nerves, with such symptoms being experienced as pain and loss of function that relate specifically to piano playing. Factors that may contribute to the incidence of PRMDs appear to include biomechanical inefficiency of wrist, finger, elbow and shoulder postures and movements, extremely long hours of practice. Another contributing factor for such results in our study can be insufficient regard for the characteristics of and structural differences between individual pianos [8].

Of the $68 \%$ who experienced pain Finkelstein's test was positive bilaterally in only $34 \%$ of the subjects. DeQuervain's tendonitis may be a result of the acute flexion of the thumb [8].

The grip strength of all 50 subjects using the handheld grip dynamometer was taken. A best of three readings was selected. A p value of 0.00 was obtained, indicating that there is a significant difference between male and female grip strength's. The females mean value being 20.18 $\mathrm{kg}$ 's, which is significantly lower than the normal mean value varying from a range of 32- 35 [11] in the normal female population. The males mean value was found to be $37.67 \mathrm{~kg}$ 's which is also significantly lower than the normal population range being 50-54[5].

The term hypermobility refers to increased movement beyond the normal range. Its prevalence is between $5 \%$ and $25 \%$ in musicians and is more common among musicians than in the general population, which may be as a result of genetically hypermobile individuals becoming top-level musicians. However, hypermobility may adversely affect the playing of an instrument in several ways. Increased laxity can result in instability, or lead to the development of synovitis or neuropathy. Larsson et al suggested that acquired laxity may be the result of chronic ligamentous stress in the first MCP and carpometacarpal (CMC) joints.[6]. In this study
Beighton's scale was used as an outcome measure to check for hypermobility, $76 \%$ fell into the criteria of having hypermobile joints.

Study limitations: Male to Female ratio was not equal, A better understanding would have been gained by comparing all types of musicians, Assessment of playing postures would have contributed to a better understanding of pain.

\section{CONCLUSION}

In conclusion this study reveals that pianists are predisposed to cumulative hand trauma disorders. With the help of the outcome measure's shown in Table 2 we are able observe that grip strength is significantly reduced, DeQuervain's is positive and hypermobility does occur in a particularly large amount of the subject population. Using Hoppmann's (1998) pain outcome measure we can conclude that pain does affect the professional pianists performance in a negative way.

Clinical implication: These cumulative hand trauma disorders can definitely be prevented on professional pianists by implementing a daily hand exercise routine in order to adequately stretch and maintain muscle property strength as well as to avoid cramping in the midst of a practice session or performance.

\section{ABBREVIATIONS}

RSI's- Repetitive Stress Injuries

PRMD's- Playing Related Musculoskeletal Disorders

\section{ACKNOWLEDGEMENTS}

I would like to thank my guide Dr. Sanket Nagrale (PT) for his constant encouragement and guidance. I also extend my sincere thanks and appreciation to Dr Rachana Dabadghav (PT) as well as Dr Dhara Kapoor for their valuable time. Lastly, I extend my warm gratitude to all subjects who have participated in this project.

\section{Conflicts of interest: None}

\section{REFERENCES}

[1]. Peter Bragge, Andrea Bialocerkowski and Joan McMeeken. A systematic review of prevalence and risk factors associated with playing-related musculoskeletal disorders in pianists. Occupational Medicine Journal (London), January 2006;56(1):2838. 
[2]. Warrington J. Hand therapy for the musician: instrument-focused rehabilitation. Hand Clinics Journal, May 2003;19(2):287-301.

[3]. Sheibani-Rad,S. Wolfe,J. Jupiter. Hand disorders in musicians: The orthopaedic surgeons role. Bone and Joint Journal 2013 Feb;95-B(2):146-50.

[4]. Hoppmann RA (1998). Musculoskeletal Problems in Instrumental Musicians. In: Sataloff RT, Brandfonbrener AG, Lederman RJ ed. Textbook of Performing Arts Medicine. 2nd ed. New York: Raven Press, pp.71-110.

[5]. Anneli Peolsson,1 Rune Hedlund2 and Birgitta OÈberg.

[6]. INTRA- AND INTER- TESTER RELIABILITY AND REFERENCE VALUES FOR HAND STRENGTH. Journal of Rehabilition Medicine 2001;33:36-41.
[7]. Spahn, Claudia, Sandra Strukely, and Andreas Lehmann. Health Conditions, Attitudes Toward Study, and Attitudes Toward Health at the Beginning of University Study: Music Students in Comparison with Other Student Populations. Medical Problems of Performing Artists 2004;19:26-33.

[8]. Lippmann, H.A. A fresh look at the overuse syndrome in musical performers: Is "overuse" or overused? Medical Problems of Performing Artists, 1991;6:57 60.

[9]. Stroller D, Brody GA. The wrist and hand/carpal tunnel syndrome. In: Stroller DW, editor. MRlinorthopedics and sports medicine. 2nd edition. Philadelphia: Lippincott-Raven; 1997;852-963.

How to cite this article:

Khushboo Tahilram, Sanket Nagrate, Ashok Shaym, Parag Sancheti. PREVALENCE OF CUMULATIVE HAND TRAUMA DISORDERS IN PIANISTS. Int J Physiother Res 2018;6(3):2759-2763. DOI: 10.16965/ijpr.2018.138 